Int. J. Dev. Biol. 57: 565-576 (2013)

doi: $10.1387 / \mathrm{ijdb} .130162 \mathrm{pc}$

\title{
Engineering metabolic pathways in plants by multigene transformation
}

\author{
UXUE ZORRILLA-LÓPEZ\#,1, GEMMA MASIP\#,1, GEMMA ARJÓ² ${ }^{2}$ CHAO BAI $^{1}$, RAVIRAJ BANAKAR ${ }^{1}$, \\ LUDOVIC BASSIE ${ }^{1}$, JUDIT BERMAN ${ }^{1}$, GEMMA FARRÉ ${ }^{1}$, BRUNA MIRALPEIX ${ }^{1}$, EDUARD PÉREZ-MASSOT ${ }^{1}$, \\ MAITE SABALZA ${ }^{1}$, GEORGINA SANAHUJA ${ }^{1}$, EVANGELIA VAMVAKA ${ }^{1}$, RICHARD M. TWYMAN ${ }^{3}$, \\ PAUL CHRISTOU ${ }^{1,4}$, CHANGFU ZHU $^{1}$ and TERESA CAPELL ${ }^{*, 1}$
}

\begin{abstract}
${ }^{1}$ Department of Plant Production and Forestry Science, School of Agrifood and Forestry Science and Engineering (ETSEA), University of Lleida-Agrotecnio Center, Lleida, Spain, ${ }^{2}$ Department of Medicine, Institute of Biomedical Research (IRB), University of Lleida, Lleida, Spain, ${ }^{3}$ School of Life Sciences, University of Warwick, Coventry, UK and ${ }^{4}$ Catalan Institution for Research and Advanced Studies (ICREA), Barcelona, Spain
\end{abstract}

\begin{abstract}
Metabolic engineering in plants can be used to increase the abundance of specific valuable metabolites, but single-point interventions generally do not improve the yields of target metabolites unless that product is immediately downstream of the intervention point and there is a plentiful supply of precursors. In many cases, an intervention is necessary at an early bottleneck, sometimes the first committed step in the pathway, but is often only successful in shifting the bottleneck downstream, sometimes also causing the accumulation of an undesirable metabolic intermediate. Occasionally it has been possible to induce multiple genes in a pathway by controlling the expression of a key regulator, such as a transcription factor, but this strategy is only possible if such master regulators exist and can be identified. A more robust approach is the simultaneous expression of multiple genes in the pathway, preferably representing every critical enzymatic step, therefore removing all bottlenecks and ensuring completely unrestricted metabolic flux. This approach requires the transfer of multiple enzyme-encoding genes to the recipient plant, which is achieved most efficiently if all genes are transferred at the same time. Here we review the state of the art in multigene transformation as applied to metabolic engineering in plants, highlighting some of the most significant recent advances in the field.
\end{abstract}

KEY WORDS: direct DNA transfer, multigene transformation, metabolic pathway, genetic engineering

\section{Introduction}

Most agronomic traits in plants are controlled by multiple genes, as is also the case for the synthesis of complex organic compounds from primary and secondary metabolisms, which often represent the outputs of long and convoluted metabolic pathways. Therefore, genetic engineering has seen a progressive change from singlegene intervention to multigene transformation to tackle increasingly ambitious objectives (Halpin, 2005).

In the early years of plant biotechnology, gene transfer experiments typically involved two transgenes: one selectable marker under the control of a constitutive promoter to facilitate the selective propagation of transformed cells, and a 'primary transgene' or 'gene of interest' which could be under the control of any promoter and was intended to alter the phenotype of the plant in a specific manner (Peremarti et al., 2010). This principle was adopted in the first examples of metabolic engineering, which involves the modulation of endogenous metabolic pathways to increase flux towards particular desirable molecules or even new molecules (Capell and Christou, 2004). Multigene transformation (MGT) is being gradually accepted as an approach to generate plants with more ambitious phenotypes, including more complex examples of metabolic engineering (Naqvi et al., 2009). To this end, methods had to be developed for the coordinated expression of largergroups

Abbreviations used in this paper: BAC, bacterial artificial chromosome; CaMV35S, cauliflower mosaic virus 35S; ORF, open reading frame; MGT, multigene transformation; PHB, polyhydroxybutyrate; PUFA, polyunsaturated fatty acid.

\footnotetext{
*Address correspondence to: Teresa Capell. University of Lleida-Agrotecnio Center, Avenida Alcalde Rovira Roure 191, E-25198 Lleida, Spain. Tel: +34 973702831 Fax: +34973 702690. e-mail: teresa.capell@pvcf.udl.cat
}

\#Note: Both authors contributed equally to this work.

Final, author-corrected PDF published online: 16 October 2013.

ISSN: Online 1696-3547, Print 0214-6282 
of genes (Capell and Christou, 2004) to attain objectives, such as: (a) enhance the activity of enzymes at multiple rate-limiting steps in target pathways, e.g. by expression of enzymes that are released from feedback inhibition; (b) increase the availability of upstream precursors to increase flux through the target pathway; (c) modulate pathway branch points to prevent the loss of flux; and (d) promote the development of sink compartments to store target compounds (Fig. 1) (Zhu et al., 2013).

Examples of metabolic engineering in plants include primary metabolic pathways (carbohydrates, amino acids, and lipids) and secondary metabolic pathways (e.g. alkaloids, terpenoids, flavonoids, lignins, quinones, and other benzoic acid derivatives; Gomez Galera et al., 2007). These pathways generate a large number of compounds that are useful to humans, including energy-rich foods, vitamins and many different pharmaceuticals. In this review, we focus on the metabolic engineering of vitamins, polyunsaturated fatty acids, and secondary metabolites, because they provide illustrative examples of applied MGT.

\section{The scope of the challenge}

The simultaneous transfer of multiple genes into plants (cotransformation) can be achieved using two main approaches, one involving linked genes (multiple genes on the same plasmid) and the other involving unlinked genes (different genes on different plasmids). The two methods can be used with both major strategies for gene transfer to plants, i.e. transformation with Agrobacterium tumefaciens and direct DNA transfer (Naqvi et al., 2009).

Multiple linked genes can be transferred by Agrobacteriummediated transformation using standard binary vectors contain-
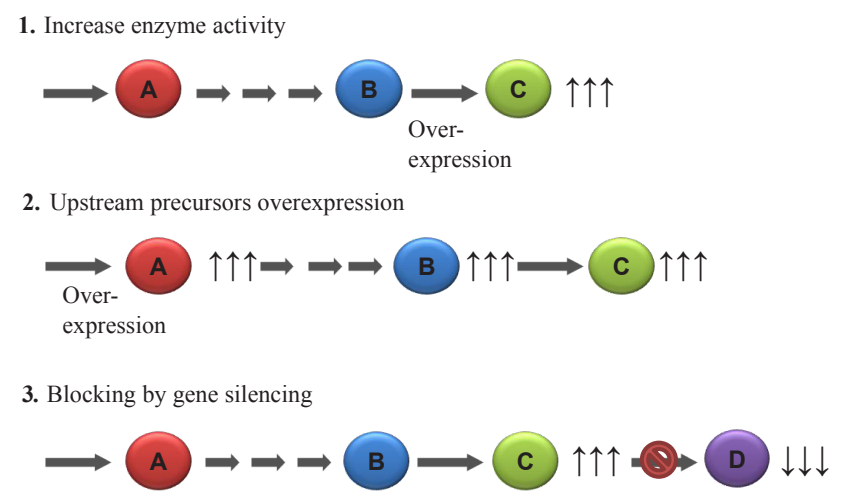

4. Generation of a metabolic sink

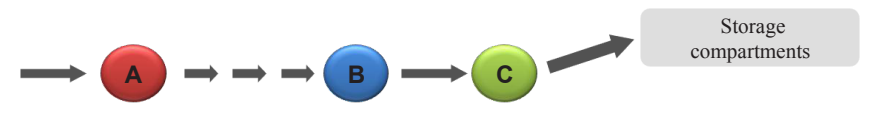

Fig. 1. Strategies to modulate organic compound levels in plants. $A$ and $B$ are the precursors of $C ; C$ is the target product; $D$ is the result of the target product conversion. (1) Modification of the activity of enzymes implicated in rate-limiting steps in the target pathway by modulation of one or two key enzymes, or multiple enzymes. (2) Upstream precursors enhancement by increasing flux through the pathway by overexpressing the enzyme(s) that catalyze(s) the first committed step of the pathway. (3) Blocked pathway branch points by RNA interference or antisense. (4) Enhanced accumulation of target metabolite by increasing sink compartments. (Zhu et al., 2013). ing multiple genes within a single T-DNA or multiple T-DNAs each containing a single gene, whereas for direct DNA transfer methods the genes can be linked on conventional vectors (Naqvi et al., 2009). The transgenes tend to integrate at a single locus, although the precise arrangement of multiple T-DNAs depends on the bacterial strain (Twyman et al., 2002). This strategy is robust for a small number of input genes, but as the number increases, the vectors become increasingly cumbersome and unstable; the effective upper capacity using standard vectors is approximately $50 \mathrm{~kb}$ due to dwindling efficiency (Naqvi et al., 2009). High-capacity binary vectors (BIBAC, BIBAC2, and TAC) that allow the transfer of up to $200 \mathrm{~kb}$ of insert DNA are discussed below.

Multiple unlinked genes can be introduced by Agrobacteriummediated transformation if the bacteria contain multiple compatible plasmids carrying separate T-DNAs or if the inoculum comprises a mixture of bacterial strains carrying different vectors; however, the ratio of different input genes is difficult to control and multiple T-DNAs tend to integrate inefficiently (Naqvi et al., 2009). Currently, only direct DNA transfer can introduce routinely and reliably multiple unlinked genes into plants, allowing plants carrying up to 15 different transgenes to be produced in one generation (Naqvi et al., 2009).

Direct DNA transfer with separate vectors usually results in transgene integration at a single random locus in the form of a multigene array, regardless of how many different transformation cassettes have been used (Altpeter et al., 2005; Kohli et al., 2006). The integrated array may contain any number of transgenes from 1 to $n$ (where $n$ is the maximum input gene number) with the distribution within the transgenic population tending to describe a skewed normal curve as would be expected from random sampling with selection against zero integration events and for larger numbers of integrated transgenes (Kohli et al., 2003). Input transgenes once integrated remain linked and do not segregate in subsequent generations (Wu et al., 2002; Altpeter et al., 2005). This feature is important when large numbers of genes are considered, because a much larger transgenic population would be required if each integration event were independent (Altpeter et al., 2005).

Chen et al., (1998) successfully transformed rice (Oryza sativa) plants by particle bombardment with 13 separate plasmids containing different marker genes, and regenerated plants carrying and expressing all the input genes at one locus. Subsequently, Wu et al., (2002) transformed rice with nine transgenes also by particle bombardment and found that nonselected transgenes were present along with the selectable marker in approximately $70 \%$ of the plants and that $56 \%$ carried seven or more genes. This percentage was much higher than expected given the independent integration frequencies, in accordance with a model suggesting that the integration of one transgene promotes the cointegration of more input DNA at the same locus (Kohli et al., 1998). All nine transgenes were expressed, and the expression of each gene was independent of the others (Wu et al., 2002) (Table 1).

The position of transgene integration also influences the level and stability of expression in both transformation methods. For example, the transgenes can be integrated at a silencing locus (position-dependent silencing) or influenced by nearby regulatory sequences, such as enhancers (Topping et al., 1991). The integration mechanism does not appear to be sequence dependent. Contrary to the prevailing view that the repetitious use of the same promoter may lead to the likelihood of transcriptional silencing, 
a number of transgenic plants have been generated containing five or more transgenes controlled by the same promoter with no untoward effects (Naqvi et al., 2009). Particle bombardment often generates large, high-copy-number transgenic loci, which are believed to be prone to instability and silencing, but there are many instances where this is not the case. For example, Golden Rice provides a clear example in which higher transgene copy numbers correspond to higher expression levels, ultimately leading to more $\beta$-carotene production in the endosperm (Datta et al., 2003). Bacillus thuringiensis (Bt)-resistant rice containing multiple transgene copies also performed well against a number of insect pests in the greenhouse (Maqbool and Christou, 1999; Maqbool et al., 2001) and under field conditions (Tu et al., 2000; Ye et al., 2001), indicating that the transgenes were expressed efficiently.

\section{Development of multigene transformation methods}

\section{Stacking and retransformation}

Prior to the development of simultaneous transfer methods suitable for many genes, multiple transgenes could be stacked in plants through successive rounds of crosses between different transgenic lines (Ma et al., 1995; Datta et al., 2002) or by the retransformation of transformed plants with additional transgenes (Jobling et al., 2002). However, both methods are time-consuming and labor-intensive because of the need of multiple breeding generations to complete the stacking process and the important segregation risk, unless all the genes can be stacked together in a homozygous plant. Both the time necessary for stacking and the segregation risk increase with the number of transgenes. In the case of sequential transformation, multiple selectable markers (or marker excision and reuse) are also required.

\section{Standard T-DNA and bombardment vectors}

Both Agrobacterium-mediated transformation and direct DNA transfer involve the use of vectors that are optimized to replicate efficiently in Escherichia coli and to facilitate subcloning, which benefit from the vector remaining small. Vectors become increasingly unstable and prone to eject DNA when too much is inserted. The shear forces during particle bombardment can lead to frag- mentation as well. It also becomes increasingly difficult to find restriction enzymes that cut at a unique site as more transgenes are introduced into the vector. Therefore, as the number of input genes increases, standard vectors are largely restricted to use with unlinked transgenes. As discussed above, Agrobacterium-mediated transformation turns out to be progressively less efficient as the number of separate T-DNAs increases, so for the highest numbers of transgenes only direct DNA transfer can be carried out with standard vectors. This problem has been solved to a certain extent by transforming plants with two bacterial strains, each carrying T-DNAs containing two or more transgenes; however, direct DNA transfer remains efficient with up to 15 unlinked transgenes and no upper limit has yet been determined. In the context of metabolic engineering, standard expression vectors have allowed the stable expression of several transgenes in maize (Zea mays) to recreate partial metabolic pathways (Zhu et al., 2008; Naqvi et al., 2010).

\section{High-capacity T-DNA vectors}

The limitations of MGT using $A$. tumefaciens have been addressed in part by the development of systems based on highcapacity artificial chromosome vectors with the ability to integrate large DNA fragments. These systems use the capacity of bacterial artificial chromosome (BAC) vectors and combine them with the components of standard binary vectors, resulting in chimeric binary vectors, such as BIBAC and TAC. Initially, these vectors still suffered from the cumbersome cloning procedure due to the lack of unique restriction sites, but this issue has been taken care of by combining the vectors with Gateway site-specific recombination technology (Vega et al., 2008). Multisite and MultiRound Gateway systems have been used to integrate up to seven genes into the plant genome (Buntru et al., 2013).

\section{Split reading frames}

The use of linker peptides can also facilitate MGT by letting several polypeptides to be encoded in a single open reading frame (ORF) controlled by a single promoter. For example, the Foot-and-mouth disease virus $2 \mathrm{~A}$ polyprotein system allows the coexpression of up to four polypeptides in tobacco (Nicotiana tabacum) plants (Møldrup et al., 2011; Lee et al., 2012; Sun et

TABLE 1

\section{EXAMPLES OF UNLINKED GENES FOR CO-TRANSFORMATION USING MULTIGENE TRANSFORMATION IN PLANTS}

\begin{tabular}{|c|c|c|c|}
\hline $\begin{array}{l}\text { Number of input } \\
\text { transgenes }\end{array}$ & Plant & Results & References \\
\hline Three & Potato & $17 \%$ of plants contained all input transgenes. & Romano et al. (2003) \\
\hline Three & Rice & $60 \%$ of all transgenic lines carried all three transgenes. & Sivamani et al. (1999); Maqbool et al. (2001) \\
\hline Four & Maize & $\begin{array}{l}\text { Introduced psy } 1 \text { and crtl (carotenoid pathway), Dhar (ascorbate pathway) and folE (folate pathway) using an } \\
\text { unlinked direct DNA transfer co-transformation strategy to increase levels of } \beta \text {-carotene, folate and ascorbate } \\
\text { in the endosperm. Achieved significant increases in all three nutrients providing the first example towards } \\
\text { 'super-nutritious' cereals. }\end{array}$ & Naqvi et al. (2009) \\
\hline Four & Rice & $50 \%$ of transgenic plants contained all four input transgenes. & Wu et al. (2002); Altpeter et al. (2005) \\
\hline Four & Rice & $\begin{array}{l}\text { More than } 20 \% \text { of the plants contained and expressed all four input transgenes (fully assembled secretory } \\
\text { antibody). }\end{array}$ & Nicholson et al. (2005) \\
\hline Five & Rice & $\begin{array}{l}\text { All transgenic plants contained at least two transgenes (mostly marker genes) and } 16 \% \text { contained all input } \\
\text { transgenes (five). }\end{array}$ & Agrawal et al. (2005) \\
\hline Up to five & Maize & $\begin{array}{l}\text { Introduced psy1, } c r t \text {, lycb, } b c h \text { and } c r t W \text { genes using an unlinked direct DNA transfer co-transformation } \\
\text { strategy aiming to generate a range of genotypes and phenotypes to dissect the carotenoid pathway. } \\
\text { Recovered maize plants with a range of phenotypes reflecting different carotenoid profiles. }\end{array}$ & Zhu et al. (2008) \\
\hline Nine & Rice & $\begin{array}{l}\text { Non-selected transgenes were present along with the selectable marker: } 70 \% \text { of the plants; } 56 \% \text { carried } \\
\text { seven or more transgenes. }\end{array}$ & Wu et al. (2002) \\
\hline Thirteen & Rice & $85 \%$ of the plants contained more than two, and $17 \%$ more than nine of the introduced transgenes. & Chen et al. (1998) \\
\hline
\end{tabular}

Adapted from (Naqvi et al., 2010). 
al., 2012). The $2 \mathrm{~A}$ linker is less than 20 amino acids in length and has the ability to cleave its own $\mathrm{C}$-terminus, thus releasing downstream polypeptides after synthesis (Halpin, 2005). In the context of metabolic engineering, the Paracoccus crtW and crt $Z$ genes were simultaneously expressed as a polyprotein with an intervening $2 \mathrm{~A}$ linker in transgenic tobacco and tomato (Solanum lycopersicum) plants to generate novel ketocarotenoids (Ralley et al., 2004). More recently, the genes for phytoene synthase and carotene desaturase have been expressed in soybean (Glycine max) seeds with an intervening $2 A$ linker, using either the $\beta$-conglycinin or the cauliflower mosaic virus 35S (CaMV35S) promoter (Kim et al., 2012). Only the $\beta$-conglycinin promoter produced seeds with orange endosperm, indicating the accumulation of $\beta$-carotene, and this corresponded to high mRNA levels in the transgenic seeds. In contrast, the CaMV35S construct generated high mRNA levels in the leaves of transgenic plants (Kim et al., 2012). Attributes and limitations of the key MGT methods are illustrated in Fig. 2.

\section{Controlling the expression of multiple transgenes}

As discussed above, a number of studies have shown that the same promoter can be used to drive multiple transgenes without negative effects, such as the strong endosperm-specific expression of three transgenes in maize achieved using the barley (Hordeum vulgare) D-hordein promoter (Naqvi et al., 2009). Other studies have indicated that repetitive use of the same promoter can encourage (although probably not directly trigger) transgene silencing (Mourrain et al., 2007). This observation may reflect several underlying factors, such as the presence of potential secondary structures that could interact in trans to promote de novo methylation, or the intrinsic activity of the promoters generating enough mRNA to saturate the polyadenylation machinery of the cell, allowing the formation of hairpin RNAs. These effects are also context dependent, based on the integration site and the juxtaposition of transgene copies, some of which may integrate 'head-to-head', thus encouraging the formation of double-stranded RNA at the junction of two opposing promoters (Kohli et al., 2006).

Therefore, although it is by no means certain that using the same promoter for different transgenes will have a negative impact on transgene expression, various strategies have been devised to avoid the possibility. Examples include the use of natural diverse promoters with the same or similar activity (for instance, five different endosperm-specific promoters were used in maize to achieve
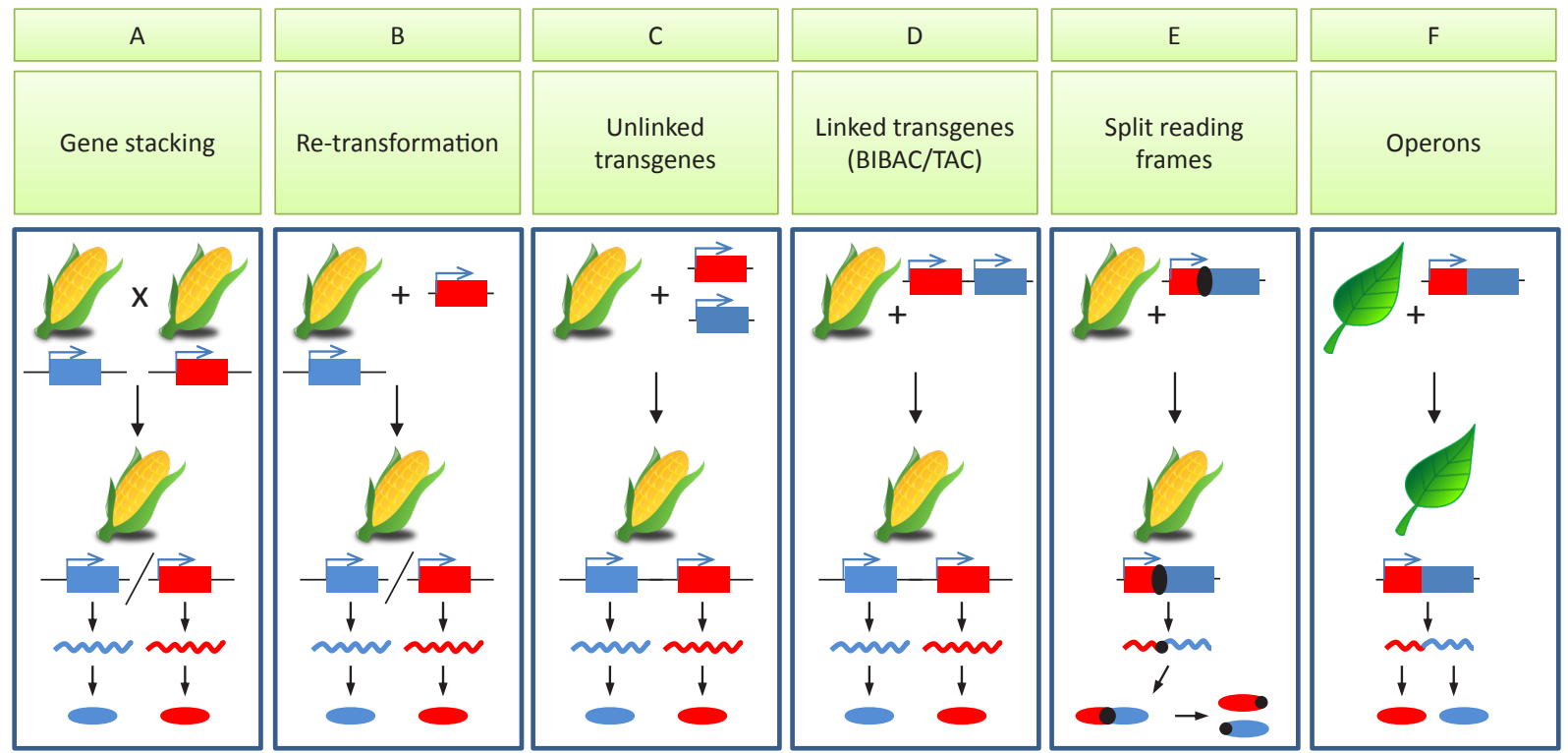

Fig. 2. Multigene transformation (MGT) methods for metabolic engineering. Schematic summary of the principles of different methods for multigene transfer. Each panel shows a different method and charts the origin, fate, and activity of two different transgenes (red and blue blocks, with promoters shown as sideways arrows). The corresponding products at the level of mRNA (undulating lines) and polypeptides (discs) are shown in matching colors. (A) In the gene stacking approach, plants already carrying transgenes 1 and 2 are crossed to bring both genes into the same line. The genes are integrated and expressed independently (diagonal slash) and may therefore segregate in later generations. Therefore, a backcross program is needed to bring the two transgenes to homozygocity. (B) In the retransformation approach, plants already carrying transgene 1 are transformed with transgene 2 , to bring both genes into the same line. The genes are integrated and expressed independently (diagonal slash) and may therefore segregate in later generations. A backcross program is also needed in this case to bring the two transgenes to homozygocity. (C) In the unlinked transformation approach, transgenes 1 and 2 are introduced into wild-type plants using separate vectors. All genes tend to integrate at the same locus, which is random, and may integrate in tandem (shown here) or in head-to-head or tail-to-tail conformations, occasionally with intervening genomic DNA sequences. Although panels (A-C) show individual transgenes as blue and red blocks, the same principles of integration and segregation also apply to groups of linked transgenes. (D) In the linked transformation approach, the transgenes are arranged in tandem on a single vector. The entire construct tends to integrate so the integrated transgenes are arranged in the same order as on the vector. This approach becomes increasingly difficult with more transgenes, unless high-capacity BIBAC/TAC vectors are employed. (E) In the split reading frame approach, two genes are expressed as a fusion protein linked by the $2 A$ peptide from the Food-and-mouth disease virus, resulting in the expression of polycistronic mRNA and a polyprotein, which is self-cleaved into proteins 1 and 2 , although each retains part of the $2 A$ peptide (black circles). (F) In the operon approach, two or more genes are expressed as an operon yielding a polycistronic mRNA, but the proteins are translated independently via internal ribosome entry sites. This approach is only feasible for genes expressed in plastids and is therefore suitable for plants, such as tobacco and a small number of other species that are amenable to plastid transformation (as shown), but not currently for cereal crops, such as maize (shown in the other panels). 
the high-level expression of five carotenogenic genes (Zhu et al., 2008), and the use of synthetic or modified promoters to reduce the amount of sequence identity (Naqvi et al., 2010; Peremarti et al., 2010).

Most promoters used in plant biotechnology are unidirectional, but bidirectional promoters are becoming increasingly useful for MGT because they allow the simultaneous expression of two gene products. For example, the human $\beta$-casein gene and a bacterial marker gene encoding luciferase have been expressed using the auxin-inducible, bidirectional mannopine synthase (mas) promoter in transgenic potato (Solanum tuberosum cv. Bintje) plants to increase their nutritional value (Chong et al., 1997).

Promoter activity depends on the availability and activity of the transcription factors, so that the expression of such transcription factors can activate several target genes. For example, ectopic expression of the maize $C 1$ and $R$ chimeric transcription factors in soybean upregulated a suite of endogenous isoflavonoid biosynthetic genes encoding phenylalanine ammonia-lyase, cinnamic acid 4-hydroxylase, chalcone isomerase, chalcone reductase, flavanone 3-hydroxylase, dihydroflavonol reductase, and flavonol synthase, doubling the isoflavonoid levels in the seeds (Yu et al., 2003).

The number of promoters can also be reduced by using the split ORF method based on the 2A linker peptide discussed above, or operon-based methods in which the genes are arranged in tandem to yield a polycistronic mRNA, of which the ORFs are translated independently. The latter method is only suitable for plastid transformation, because the plastid genome is arranged into operons reflecting its prokaryotic origin. Plastid transformation

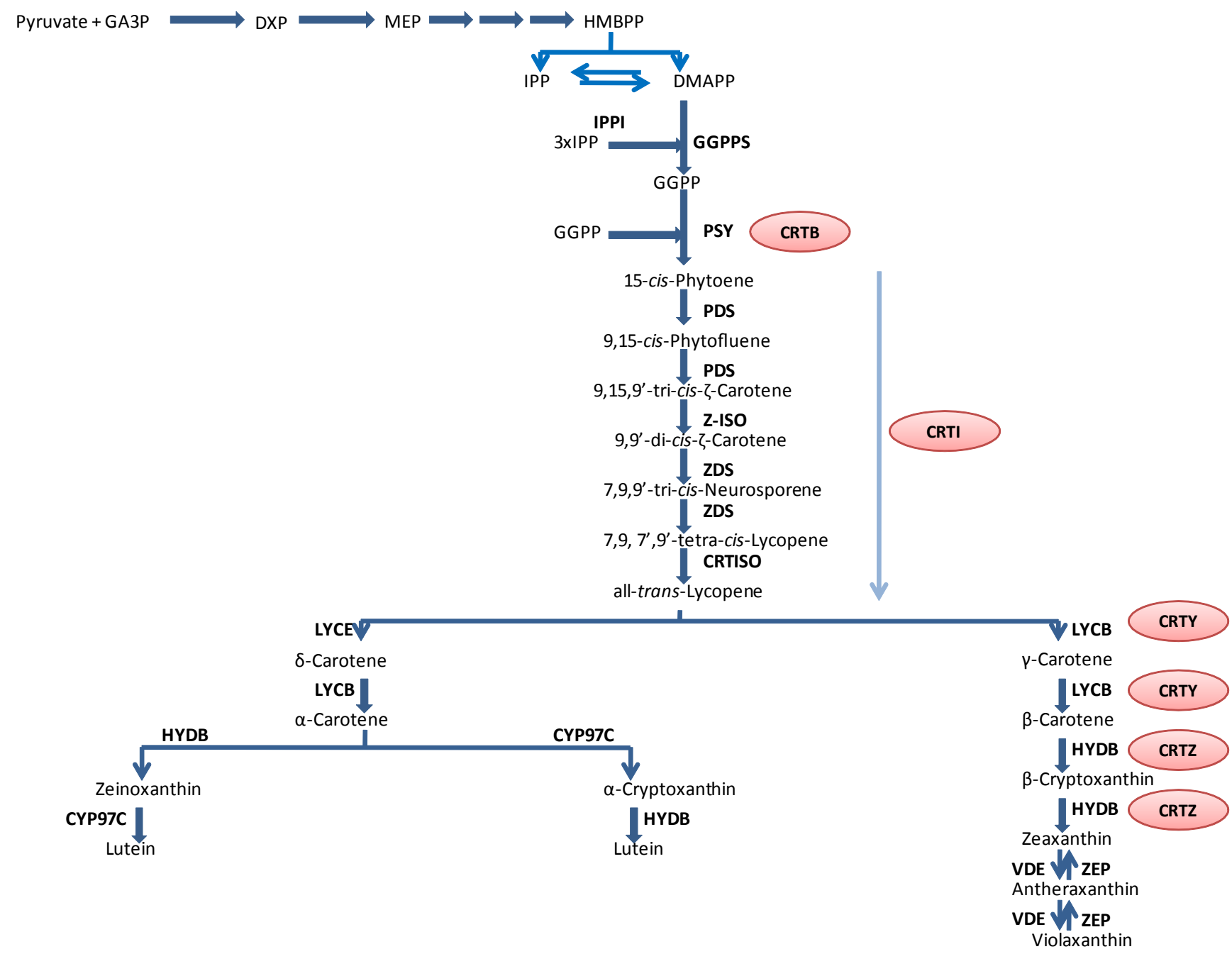

Fig. 3. Carotenoid biosynthetic pathway in plants and equivalent steps in bacteria. Enzymes in the red ovals are from bacteria. Abbreviations: CRTB, bacterial phytoene synthase; CRTI, bacterial phytoene desaturase, which catalyze all desaturation and isomerization reaction from phytoene to lycopene; CRTISO, carotenoid isomerase; CRTY, bacterial lycopene $\beta$-cyclase; CRTZ, bacterial $\beta$-carotene hydroxylase; CYP97C, heme-containing cytochrome P450 carotene $\varepsilon$-ring hydroxylase; DMAPP, dimethylallyl diphosphate; DXP, 1-deoxy-D-xylulose 5-phosphate; DXR, DXP reductoisomerase; DXS, DXP synthase; GA3P, glyceraldehyde 3-phosphate; GGPP, geranylgeranyl diphosphate; GGPPS, GGPP synthase; HDR, HMBPP reductase; HMBPP, hydroxymethylbutenyl 4-diphosphate; $H Y D B$, $\beta$-carotene hydroxylase [non-heme di-iron $\beta$-carotene hydroxylase (BCH) and heme-containing cytochrome P450 $\beta$-ring hydroxyalses (CYP97A and CYP97B)]; IPP, isopentenyl diphosphate; IPPI, isopentenyl diphosphate isomerase; LYCB, Iycopene $\beta$-Cyclase; LYCE, lycopene $\varepsilon$-cyclase; MEP, methylerythritol 4-phosphate; PDS, phytoene desaturase; PSY, phytoene synthase; VDE, violaxanthin deepoxidase;

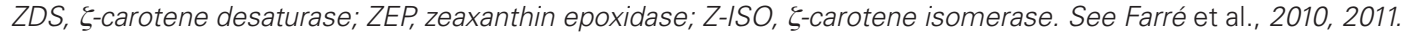


with operon-like multigene constructs has been used to produce astaxanthin in tobacco by expressing $\beta$-carotene ketolase and $\beta$-carotene hydroxylase (Hasunuma et al., 2008). Similarly, the production of polyhydroxybutyric acid $(\mathrm{PHB})$ in plastids has been achieved by expressing the phbC-phbB-phbA genes of Ralstonia eutropha using the T7g10 promoter (Lössl et al., 2005).

\section{Combinatorial transformation}

One of the key challenges in metabolic engineering is that any targeted pathway must be understood in detail before interventions are made, to avoid wasting resources on the development of futile transgenic lines. In other words, for the longer and more complex pathways, large numbers of transgenic lines must be developed and tested independently before the most suitable intervention points are identified. Combinatorial transformation, a concept developed by Zhu etal., (2008), elegantly solves this challenge and simultaneously turns the irritating random nature of transgene integration during gene transfer to plants into an advantage. The approach is based on the creation of metabolic libraries comprising plants transformed with random selections of particular transgenes. For example, the targeted analysis of five transgenes would require the generation of five transgenic lines carrying individual transgenes, plus other lines carrying combinations (perhaps created by stacking), each of which would then be subject to metabolic profiling to determine the impact on the target pathway. In combinatorial transformation, this idea is reversed by taking advantage of the scattergun nature of transgene integration: instead of selecting specific transgenic lines containing particular combinations of transgenes, the aim is to look at all the transgenic lines and with as much diversity as possible. Combinatorial transformation with five transgenes would therefore generate many different lines, some containing single transgenes, others two or three or four, and some with all five. These lines constitute a diverse library of metabolic potential, produced in a single generation. Hence, subsequent metabolic profiling helps to identify bottlenecks in the pathway and the best intervention points, even if effective intervention can only be achieved by multiple transgenes. The combinatorial approach is analogous to the use of factorial designs to test different parameters rather than focusing on the variation of one parameter at a time.

In the context of metabolic engineering, the carotenoid biosynthesis pathway in maize has been investigated by combinatorial transformation, allowing the identification and complementation of rate-limiting steps that affect the accumulation of $\beta$-carotene and other nutritionally important carotenoids, such as lutein, zeaxanthin, and lycopene. This approach has also allowed the pathway to be extended beyond its natural end-point to produce compounds, such as astaxanthin, revealing competition between $\beta$-carotene
Fig. 4. Vitamin $E$ biosynthesis in plants (Farré et al., 2012). Tocochromanols are synthesized on the inner chloroplast membrane from precursors derived from the shikimate and methylerythritol 4-phosphate (MEP) pathways. The shikimate pathway contributes the head-group precursor homogentisic acid (HGA), whereas the MEP pathway gives rise to the side-chain precursors phytyldiphosphate (PDP) and geranylgeranyldiphosphate (GGDP). The first committed step in the reaction is the cytosolic conversion of p-hydroxyphenylpyruvic acid (HPP) to HGA by p-hydroxyphenylpyruvic acid dioxygenase (HPPD). HGA is then prenylated with either PDP or GGDP to produce the intermediates 2-methyl-6-phytyl benzoquinone (MPBQ) and 2-methyl-6-geranylgerany/plastoquinol (MGGBQ). A second methyl group is added by MPBO methyltransferase (MPBOMT) in the tocopherol branch and MGGBO methyltransferase (MGGBQ-MT) in the tocotrienol branch, producing the intermediates 3-dimethyl-5-phytyl-1,4-benzoquinone (DMPBQ) and 2-dimethyl-6-geranylgeranylbenzoquinol (DMGGBQ). All four of these intermediates are substrates for tocopherol cyclase (TC), which produces $\delta$ and $\gamma$ tocopherols and tocotrienols. Finally, $\gamma$-tocopherol methyltransferase $(\gamma$-TMT) catalyses a second ring methylation to yield $\alpha$ and $\beta$ tocopherols and tocotrienols. Other abbreviations: GGDR, geranylgeranyl diphosphate reductase; HGGT; homogentisate geranylgeranyl transferase; HPT, homogentisate phytyltransferase. PDS, VTE1, VTE2, VTE3 and VTE4 correspond to genes cloned from Arabidopsis Thaliana that are homologous to HPPD, HPT, MPBQ-MT, TC, and $\gamma$-TMT genes, respectively.

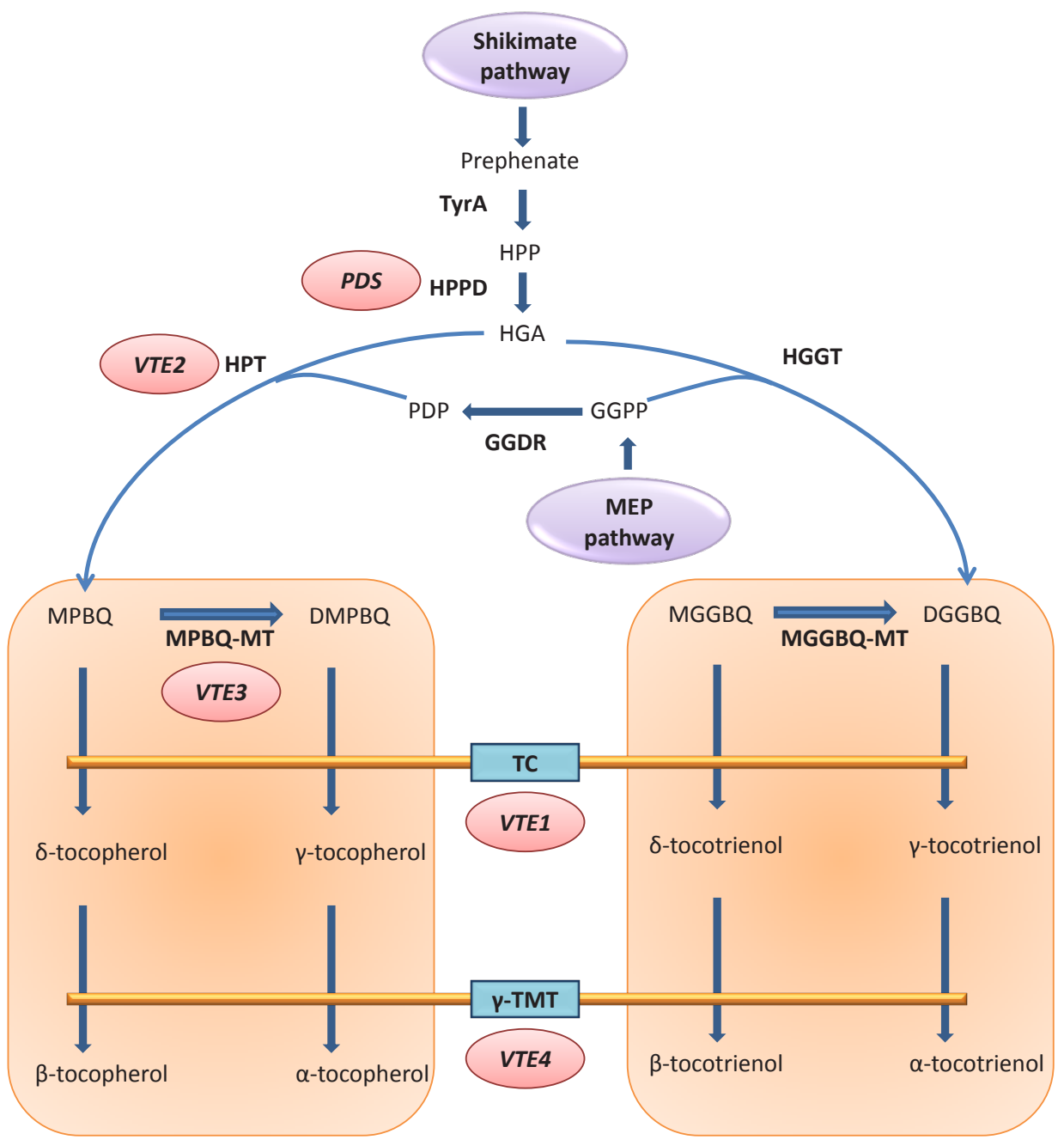




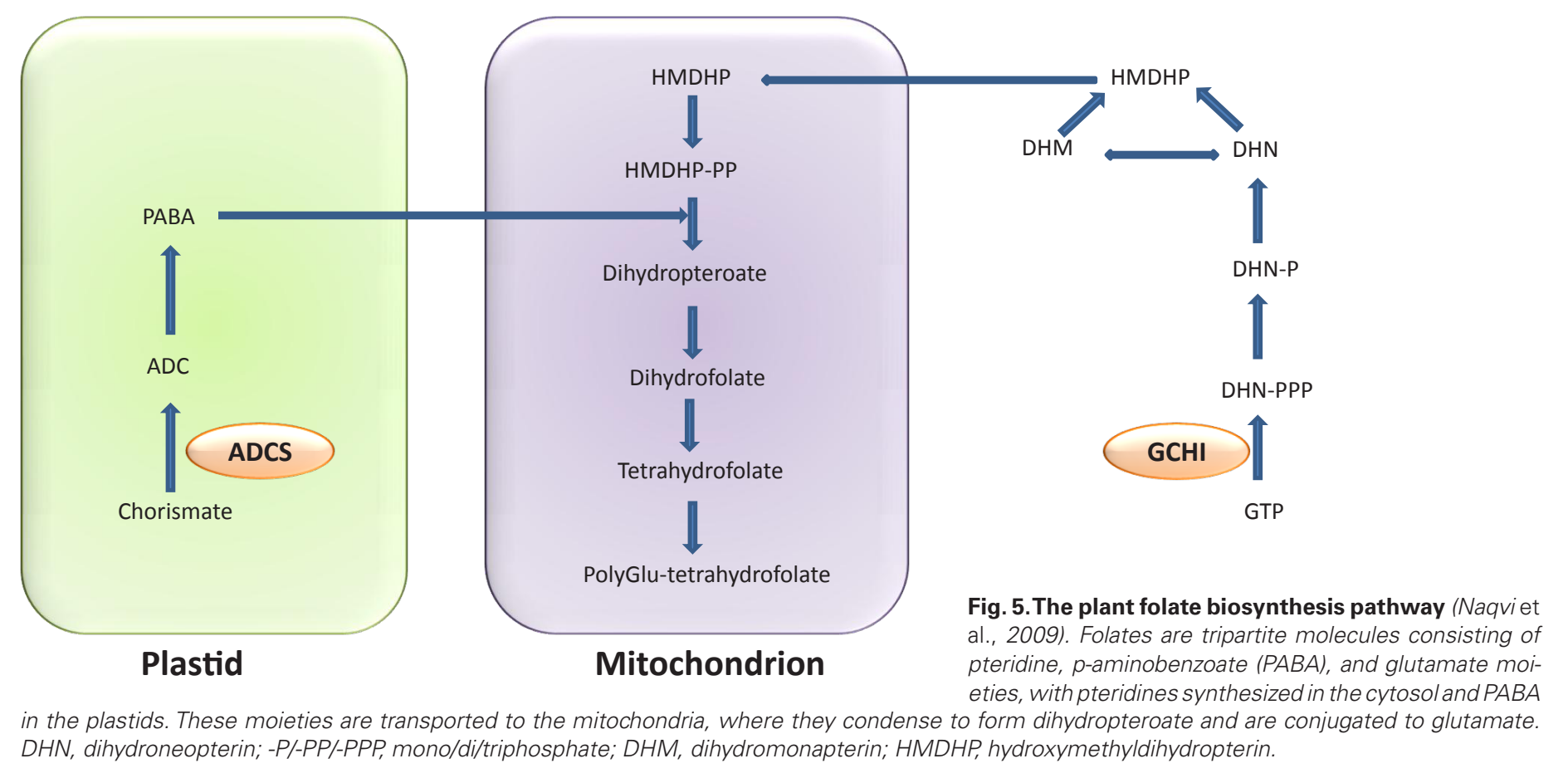

hydroxylase and bacterial $\beta$-carotene ketolase for substrates (Zhu et al., 2008).

Combinatorial transformation has also been used to combine genes from several different metabolic pathways to identify combinations that allow the simultaneous accumulation of different compounds. For example, maize plants had been generated that coincidently accumulated high levels of vitamins $\mathrm{A}, \mathrm{C}$ and $\mathrm{B}_{9}$ (folate) (Naqvi et al., 2009).

\section{Synthetic biology as the next step for multigene meta- bolic engineering}

Synthetic biology describes the de novo assembly of genetic systems using prevalidated components (Haseloff and Ajioka, 2009). In the context of metabolic engineering in plants, a synthetic biology approach would utilize specific promoters, genes, and other regulatory elements to create ideal genetic circuits that facilitate the accumulation of particular metabolites. The concept of synthetic biology creates engineering and mathematical modeling to predict and test the behavior of the resulting system, which can be considered as the next step in multigene metabolic engineering because it removes any dependence on naturally occurring sequences and allows the design of ideal functional genetic circuits from first principles. Thus far, most work on synthetic biology has been accomplished with microorganisms, in spite of still some limiting factors, such as the ability of current methods to assemble complex DNA molecules encoding multiple genetic components in predefined arrangements (Weber et al., 2011). Simple synthetic biology approaches have been described in plants, mostly in the context of signaling pathways and development, but also in the development of phytodetectors (Zurbriggen et al., 2012) and biofortified crops (Naqvi et al., 2009).

The use of synthetic biology in development as well as metabolism is important because it not only controls the metabolic capacity of a cell, but also steps one level up in terms of organization and use of particular promoters and genes that control developmental processes to generate novel tissues, in which the cells have specialized biosynthetic or storage functions to accumulate target products in particular organs. This approach will facilitate the achievement of goals that are unattainable by conventional genetic engineering, such as the development of novel organisms with medical functions, the production of biofuels, and the removal of hazardous waste (Purnick and Weiss, 2009).

\section{Applications of MGT for pathway engineering}

Metabolic pathways leading to complex organic molecules, such as vitamins (Figs 3, 4 and 5), polyunsaturated fatty acids (Fig. 6), and secondary metabolites often comprise a large number of genes, enzymes, and feedback mechanisms, limiting our ability to modulate these pathways by single-gene transformation. The introduction of multiple genes is necessary to understand the bottlenecks and identify and complement the rate-limiting steps (Zhu et al., 2008).

The metabolic engineering of vitamin synthesis is necessary because many staple crops lack adequate amounts of these vital compounds. For example, vitamin $A$ is required (as retinal) for blindness prevention and (as retinoic acid) for development and maintenance of a healthy immune system; vitamin $\mathrm{E}$ is an important antioxidant defense compound that quenches free radicals and protects against lipid peroxidation (Zhu et al., 2013); and folate plays a central metabolic role, including DNA synthesis. None of these compounds are present at high levels in cereal grains, and more than one half of the world's population suffers from deficiency diseases because they rely on a cereal-based diet (Fitzpatrick et al., 2012). Consequently, multigene metabolic engineering in plants has focused on carotenoid biosynthesis (vitamin A), tocochromanol synthesis (vitamin E), and folate synthesis (Naqvi etal., 2009, 2011).

Polyunsaturated fatty acids (PUFAs) are lipids that are needed 
not only as energy molecules, but for more specific activities, such as maintenance of the nervous system, the immune system, and prevention of atherosclerosis (Benatti et al., 2004). PUFAs with dual roles as energy providers and essential nutrients include the omega-3 group, e.g. $\alpha$-linolenic acid (ALA), eicosapentaenoic acid (EPA), and docosahexaenoic acid (DHA), and the omega-6 group, e.g. linoleic acid (LA) and arachidonic acid (AA) (Fig. 6). Humans cannot synthetize PUFAs because they lack methyl-end desaturases, and such modules must be accessed through the diet, particularly in fish and other seafood (Benatti et al., 2004). Because there is little access to seafood across large parts of the world, metabolic engineering has been used to increase the abundance of essential PUFAs in transgenic plants.

Finally, secondary metabolites are complex molecules that are not required for housekeeping functions, but, nevertheless, provide advantages to plants, e.g. by attracting pollinators and repelling pests and pathogens. The three major types of secondary metabolite are the alkaloids, terpenoids/isoprenoids, and phenolics. Because plants have evolved to produce such molecules to control the behavior of animals and microbes, many secondary metabolites have pharmacological properties in humans or can be used as flavors, fragrances, and crop protection products (Miralpeix et al., 2013).

\section{Vitamins}

The first use of multigene engineering to modulate the vitamin content of plants was the development of Golden Rice (Ye et al., 2000). This is a transgenic rice line engineered to produce high levels of $\beta$-carotene through the expression of Pantoea ananatis phytoene desaturase ( $\mathrm{PaCrt}$ ), daffodil (Narcissus spp.) phytoene synthase (psy1), and daffodil lycopene $\beta$-cyclase (lycb) (Fig. 3). The original Golden Rice line produced $1.6 \mu \mathrm{g} / \mathrm{g}$ dry weight (DW) of $\beta$-carotene, but the replacement of daffodil psy 1 with the more active maize enzyme in Golden Rice 2 boosted the $\beta$-carotene content to $31 \mu \mathrm{g} / \mathrm{g}$ DW (Paine et al., 2005).

General strategies to increase carotenoid levels in plants include increasing the availability of carotenoid precursors, expressing enzymes in the common (linear) part of the pathway, and shifting the flux from the $\alpha$ - to the $\beta$-branch (Fig. 3). In canola (Brassica napus), Agrobacterium-mediated MGT was used to introduce seven different transgenes in order to reconstruct the entire carotenoid pathway, including an extension which allowed the production of ketocarotenoids (Fujisawa et al., 2009). The input genes were isopentenyl pyrophosphate isomerase (idl), geranylgeranyldiphosphate(GGPP) synthase (CrtE), bacterial phytoene synthase (CrtB), Crtl, lycopene $\beta$-cyclase ( $\mathrm{Cr}$ Y $)$, and the genes for two additional enzymes ( $\mathrm{Cr} Z \mathrm{Z}$ and $\mathrm{CrtW}$ that catalyze downstream steps converting $\beta$-carotene into ketocarotenoids. This strategy achieved a 30-fold increase in total carotenoid content (657 $\mu \mathrm{g} / \mathrm{g}$ fresh weight [FW]) and a 1070fold increase in $\beta$-carotene (214 $\mu \mathrm{g} / \mathrm{g} \mathrm{FW})$. In maize, MGT with maize psy1, PaCrtl, lycb of Gentiana lutea (great yellow gentian) (Gllycb), and Paracoccus sp. CrtW produced $35.64 \mu \mathrm{g} / \mathrm{g}$ DW of $\beta$ carotene (Zhu et al., 2008). Carotenoid multigene engineering has also been applied in tomato, potato, and wheat (Triticum aestivum) (Dharmapuri et al., 2002; Diretto et al., 2007; Cong et al., 2009).

The folate biosynthesis pathway (Fig. 4) involves the integration of two independent branches (pterin and p-aminobenzoate). The total folate content can be increased by modulating individual enzymes in either branch, but the best results are achieved by the simultaneous modulation of both branches by multigene engineering. In the most successful report, a 100-fold increase of total folate $(38.3 \mathrm{nmol} / \mathrm{g} \mathrm{FW})$ was achieved in rice by expression of the Arabidopsis thaliana GTP cyclohydrolase $1(\mathrm{GCH} 1)$ and aminodeoxychorismate synthase (ADCS) that enhances the the cytosolic (pterin) branch and the plastidic p-aminobenzoate branch of the pathway, respectively (Storozhenko et al., 2007).

The synthesis of tocochromanols (vitamin E) involves a complex pathway (Fig. 5). Vitamin E levels can be elevated by increasing the total tocopherol content or enhancing the production of specific tocochromanols with the most potent vitamin $E$ activity $(\alpha-$ tocopherol). The constitutive expression of two Arabidopsis cDNA

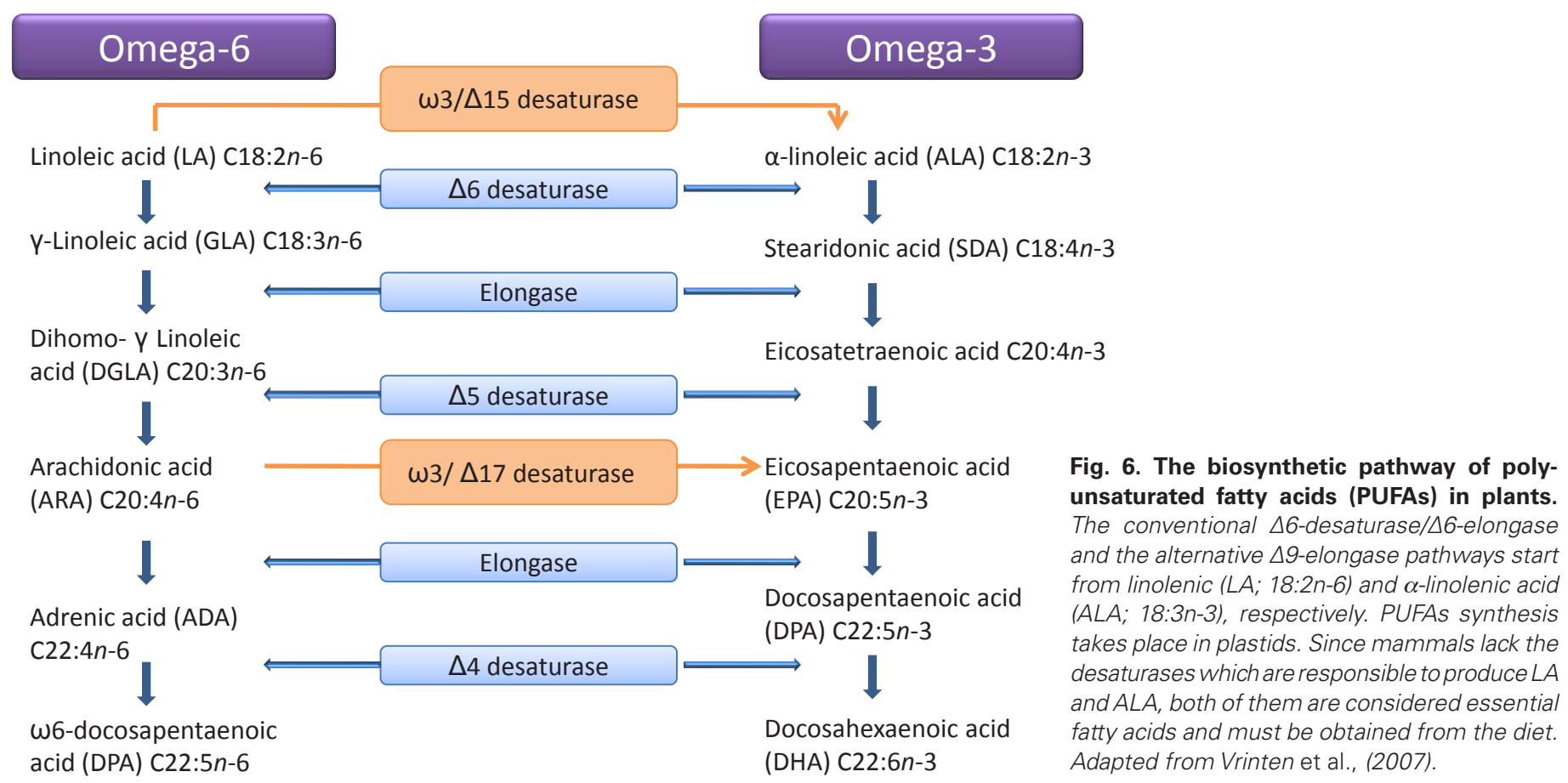


clones encoding p-hydroxyphenylpyruvate dioxygenase (HPPD) and 2-methyl-6-phytylplastoquinol methyltransferase (MPBQ MT) increased the tocopherol content 3-fold in transgenic maize (Naqvi et al., 2011). In soybean, the expression of homogentisate phytyltransferase (HPT1), HPPD, TyrA (responsible for the synthesis of HPP from prephenate), and geranylgeranyldiphosphate reductase (GGDR) increased the tocochromanol content by 15 -fold (4806 $\mu \mathrm{g} / \mathrm{g}$ DW) (Karunanandaa et al., 2005).

The current state-of-the-art in vitamin engineering is the simultaneous modulation of multiple vitamin pathways in the same plant, as reported by Naqvi et al. (2009) through the expression of maize psy1 and PaCrtl, representing the carotenoid biosynthesis pathway, rice dehydroascorbate reductase (dhar) to increase vitamin C (ascorbate) levels, and E. coli FolE to enhance folate accumulation (Figs 3, 4 and 5). The transgenic kernels contained 169 -fold the normal amount of $\beta$-carotene, 6 -fold the normal amount of ascorbate, and 2-fold the normal amount of folate.

\section{Long-chain polyunsaturated fatty acids}

Several different oil-seed crops have been transformed with multiple genes representing the PUFA biosynthesis pathway (Sayanova and Napier, 2004). For example, to obtain very long chain PUFAs from ALA and LA, it is necessary to introduce at least three transgenes encoding the desaturases and elongases required for sequential enzymatic reactions (Beaudoin et al., 2000; Hong, 2002) (Fig. 6). Soybean seeds with higher levels of EPA have been produced by expressing Mortierella alpina $\Delta 6$-desaturase, $\Delta 5$-desaturase and $\Delta 6$-elongase transgenes plus omega- $3 \Delta 17$ desaturase from Saprolegnia diclina, and omega-3 $\Delta 15$-desaturase from Arabidopsis (Kinney et al., 2011) (Fig. 6). This strategy was chosen to maximize the accumulation of omega-3 very long chain PUFAs by converting omega-6 PUFAs into their omega-3 counterparts.

\section{Secondary metabolites}

Although metabolic engineering can be used to enhance the production of secondary metabolites, it is challenging because of the complexity of the pathways and the shuffling of precursors and intermediates between compartments (Miralpeix et al., 2013). The availability of precursors can be augmented by modulating the accessibility of basic nitrogen, carbon, and sulfur compounds, including the synthesis of amino acids, such as phenylalanine, tryptophan and tyrosine, and enhance both primary and secondary metabolism simultaneously (Pichersky and Gang, 2000).

Artemisinin is used as a drug against malaria caused by Plasmodium falciparum and has been produced in transgenic tobacco by multigene engineering (Farhi et al., 2011). A mega-vector was constructed, containing the Artemisia annua (sweet wormwood) genes for cytochrome P450 reductase (CPR), amorpha-4,11diene synthase $(A D S)$, amorpha-4,11-diene monooxygenase (CYP71AV1), and artemisinic aldehyde $\Delta-11(13)$ reductase (DBR2), and the yeast 3-hydroxy-3-methylglutaryl coenzyme A reductase (HMGR), each under the control of a different promoter. In a separate vector, the $A D S$ sequence was fused to a COX4 signal peptide for import into the mitochondria, to boost the production of terpenoids. The vectors were introduced into tobacco plants by Agrobacterium-mediated transformation and the resulting transgenic plants produced amorpha-4,11-diene at levels of 26-72 ng/g FW (normal ADS) and 137-827 ng/g fresh weight (mitochondrial ADS).

MGT has also been used to boost the production of the natural polyester PHB in sugarcane (Saccharum spp.), but required the introduction of the enzymes $\beta$-ketothiolase (PHAA), acetoacetylreductase (PHAB), and $\mathrm{PHB}$ synthase (PHAC) from Ralstonia eutropha, and was achieved by particle bombardment with separate vectors (Petrasovits et al., 2007). The resulting plants accumulated PHB to $1.88 \%$ DW in their leaves.

Opium poppy (Papaver somniferum) is one of the most important medicinal plants because it is the source of the cancer drug noscapine, the muscle relaxant papaverine, and analgesic and narcotic drugs, such as morphine and codeine. Morphine-type alkaloids have been produced in plant cell cultures since the 1970s (Rischer et al., 2013). MGT has been used in this case to inhibit several genes in a pathway by virus-induced gene silencing to gain insight into the final six steps of morphine biosynthesis (Wijekoon and Facchini, 2012). The inhibition of SalSyn, SalR, T6ODM and CODM protein levels correlated with lower morphine yields and a substantial increase in the accumulation of reticuline, salutaridine, thebaine, and codeine, respectively. In contrast, the inhibition of SalAT and COR resulted in higher levels of salutaridine and reticuline.

\section{Looking to the future}

MGT is becoming essential as a strategy for metabolic engineering because it is clear that single-point interventions are inadequate to achieve ambitious metabolic goals even when dealing with a single pathway, and are unsuitable for the simultaneous engineering of different pathways, as illustrated by multivitamin corn.

Although it is now straightforward to introduce and express 5-10 transgenes in the same transgenic line, this is not the ceiling of the technique but rather the current status quo. Theoretically, there is no maximum number of transgenes that can be introduced at once, as demonstrated in microbes in which large, low-copy number vectors, such as BACs, P1-derived artificial chromosomes in bacteria, and yeast artificial chromosomes, are suitable for the introduction of hundreds of genes. This trend is emerging in plants, with large-capacity T-DNA-based vectors, but unlinked genes and direct DNA transfer allow the use of smaller vectors and achieve the same goals, because integration occurs at a single locus, therefore providing a suitable platform for strategies based on synthetic biology. In order to improve the potential of multigene transfer, a combination of linked and unlinked strategies could be developed to engineer more complex novel high-flux pathways and even combine these with the strategies shown in Fig. 1.

Multigene transfer must still overcome certain practical barriers that occur after gene integration, e.g. silencing, transgene rearrangement, and interactions between transgenes. As discussed above, repeated use of the same promoter does not necessarily encourage silencing, but may be a factor when another trigger is present; therefore, strategies have been developed based on promoter diversity or use of artificial or chimeric promoters to reduce the risk of unproductive interactions (Peremarti et al., 2010). Novel strategies to assess the risk of transgene rearrangement and interactions with surrounding loci include site-specific recombination, targeted integration, and the use of engineered restriction enzymes, especially those based on zinc fingers and transcription activator-like effectors (Li et al., 2012). 
Metabolic pathways display a high degree of connectivity in larger networks, especially when metabolites are involved in two or more pathways; hence, the introduction of a large number of input genes has the potential to generate unintended and unpredicted effects. However, an interesting study showed that transfer of the entire pathway for dhurrin biosynthesis (a tyrosine-derived cyanogenic glucoside) into Arabidopsis had no significant impact on the wider transcriptome and metabolome, whereas the transfer of an incomplete pathway induced significant changes in morphology, transcriptome, and metabolome, probably through metabolic crosstalk or detoxification reactions (Kristensen et al., 2005). Monitoring changes at the gene, transcript, protein, and metabolite levels is a challenge. In the future, it will be necessary to integrate these data in the context of systems biology, in which modeling is becoming a standard analytical tool for understanding whole biological systems and predicting gene behavior (Purnick and Weiss, 2009). Systems biology is also a necessary component of synthetic biology, because it is critical to foresee the behavior of synthetic genetic circuits in the context of the wider organism. Advances in systems biology and synthetic biology offer enormous potential in terms of development of novel materials and energy sources, improvement of agronomic traits, human health applications, and a better understanding of natural gene regulation (Naqvi et al., 2009; Zurbriggen et al., 2012). For example, the expression of three genes required for the conversion of acetyl-CoA to $\mathrm{PHB}$ in plastids allows the production of bioplastics in plants (BohmertTatarev et al., 2011), and the introduction of five genes of the $E$. coli glycolate catabolic pathway into Arabidopsis thaliana plastids reduces the loss of fixed carbon and nitrogen during photorespiration, increasing plant biomass (Kebeish et al., 2007).

\section{Acknowledgments}

Research at the Universitat de Lleida is supported by the Ministerio de Ciencia e Innovación (grants no. BFU2007-61413, BIO2011-23324, BIO02011-22525, PIM2010PKB-0074, Acciones complementarias BIO2007-30738-E and BIO2011-22525, and the Centre CONSOLIDER on Agrigenomics), the European Union Framework 7 Program (SmartCell Integrated Project 222716), the European Research Council IDEAS Advanced Grant Program (BIOFORCE) (to PC), the European Cooperation in Science and Technology (COST Action FA0804), and RecerCaixa.

\section{References}

AGRAWAL P K, KOHLI A, TWYMAN R M, CHRISTOU P (2005). Transformation of plants with multiple cassettes generates simple transgene integration patterns and high expression levels. Mol Breed 16: 247-260.

ALTPETER F, BAISAKHN, BEACHYR, BOCK R, CAPELLT, CHRISTOU P, DANIELL H, DATTAK, DATTAS, DIX P J, FAUQUET C, HUANG N, KOHLI A, MOOIBROEK H, NICHOLSON L, NGUYEN T H, NUGENT G, RAEMAKERS K, ROMANO A, SOMERS D A, STOGER E, TAYLOR N, VISSER R (2005). Particle bombardment and the genetic enhancement of crops: myths and realities. MolBreed 15:305-327.

BEAUDOIN F, MICHAELSON L V, HEY S J, LEWIS M J, SHEWRY P R, SAYANOVA O, NAPIER JA (2000). Heterologous reconstitution in yeast of the polyunsaturated fatty acid biosynthetic pathway. Proc Natl Acad Sci USA 97: 6421-6426.

BENATTI P, PELUSO G, NICOLAI R, CALVANI M (2004). Polyunsaturated fatty acids: Biochemical, nutritional and epigenetic properties. J Am Coll Nutr 23: 281-302.

BOHMERT-TATAREV K, MCAVOY S, DAUGHTRY S, PEOPLES O P, SNELL K D (2011). High levels of bioplastic are produced in fertile transplastomic tobacco plants engineered with a synthetic operon for the production of polyhydroxybutyrate. Plant Physiol 155: 1690-1708.

BUNTRU M, GÄRTNER S, STAIB L, KREUZALER F, SCHLAICHN (2013). Delivery of multiple transgenes to plant cells by an improved version of MultiRound Gateway technology. Transgenic Res 22: 153-167

CAPELL T, CHRISTOU P (2004). Progress in plant metabolic engineering. Curr Opin Biotechnol 15: 148-154.

CHEN L, MARMEY P, TAYLOR N J, BRIZARD J-P, ESPINOZA C, D'CRUZ P, HUET H, ZHANG S, DE KOCHKO A, BEACHY R N, FAUQUET C M (1998). Expression and inheritance of multiple transgenes in rice plants. Nat Biotechnol16:1060-1064.

CHONG D K X, ROBERTS W, ARAKAWA T, ILLES K, BAGI G, SLATTERY C W, LANGRIDGE W H R (1997). Expression of the human milk protein $\beta$-casein in transgenic potato plants. Transgenic Res 6: 289-296.

CONG L, WANG C, CHEN L, LIU H, YANG G, HE G (2009). Expression of phytoene synthase 1 and carotene desaturase $\mathrm{crtl}$ genes result in an increase in the total carotenoids content in transgenic elite wheat (Triticum aestivum L.). J Agric Food Chem 57: 8652-8660.

DATTA K, BAISAKH N, MAUNG THET K, TU J, DATTA S K (2002). Pyramiding transgenes for multiple resistance in rice against bacterial blight, yellow stem borer and sheath blight. Theor Appl Genet 106: 1-8.

DATTA K, BAISAKH N, OLIVA N, TORRIZO L, ABRIGO E, TAN J, RAI M, REHANA S, AL-BABILI S, BEYER P, POTRYKUS I, DATTA S K (2003). Bioengineered 'golden' indica rice cultivars with $\beta$-carotene metabolism in the endosperm with hygromycin and mannose selection systems. Plant Biotechnol J 1: 81-90.

DHARMAPURI S, ROSATI C, PALLARA P, AQUILANI R, BOUVIER F, CAMARA $B$, GIULIANO G (2002). Metabolic engineering of xanthophyll content in tomato fruits. FEBS Lett 519: 30-34.

DIRETTO G, AL-BABILI S, TAVAZZA R, PAPACCHIOLI V, BEYER P, GIULIANO G (2007). Metabolic engineering of potato carotenoid content through tuber-specific overexpression of a bacterial mini-pathway. PLoS One 2:e350.

FARHI M, MARHEVKA E, BEN-ARI J, ALGAMAS-DIMANTOV A, LIANG Z, ZEEVI V, EDELBAUM O, SPITZER-RIMON B, ABELIOVICH H, SCHWARTZB, TZFIRA T, VAINSTAIN A (2011). Generation of the potent anti-malarial drug artemisinin in tobacco. Nat Biotechnol 29: 1072-1074.

FARRÉ G, SANAHUJA G, NAQVIS, BAI C, CAPELL T, ZHU C, CHRISTOU P (2010) Travel advice on the road to carotenoids in plants. Plant Sci 179: 28-48.

FARRÉ G, BAI C, TWYMAN R M, CAPELL T, CHRISTOU P, ZHU C (2011). Nutritious crops producing multiple carotenoids - a metabolic balancing act. Trends Plant Sci 16: 532-540.

FARRÉ G, ZORRILLA U, BERMAN J, ZHU C, CHRISTOU P, CAPELL T (2012). Increasing the vitamin $E$ content of food by in-plant production. CAB Rev. 7: 030 doi: 10.1079/PAVSNNR20127030.

FITZPATRICKTB, BASSET G J C, BORELP, CARRARI F, DELLAPENNAD, FRASER P D, HELLMANN H, OSORIO S, ROTHAN C, VALPUESTA V, CARIS-VEYRAR C, FERNIE A R (2012). Vitamin deficiencies in humans: can plant science help? Plant Cell 24: 395-414

FUJISAWAM, TAKITAE, HARADAH, SAKURAIN, SUZUKI H, OHYAMAK, SHIBATA D, MISAWAN (2009). Pathway engineering of Brassica napus seeds using multiple key enzyme genes involved in ketocarotenoid formation. J Exp Bot60: 1319-1332.

GOMEZ GALERA S, PELACHO A M, GENE A, CAPELL T, CHRISTOU P (2007). The genetic manipulation of medicinal and aromatic plants. Plant Cell Rep 26: 1689-1715.

HALPIN C (2005). Gene stacking in transgenic plants - the challenge for 21st century plant biotechnology. Plant Biotechnol J 3: 141-155.

HASELOFF J, AJIOKAJ (2009). Synthetic biology: history, challenges and prospects. J R Soc Interface 6: S389-S391.

HASUNUMA T, MIYAZAWA S-I, YOSHIMURA S, SHINZAKI Y, TOMIZAWA K-I, SHINDO K, CHOI S-K, MISAWAN, MIYAKE C (2008). Biosynthesis of astaxanthin in tobacco leaves by transplastomic engineering. Plant $J$ 55: 857-868.

HONG H, DATTA N, REED D W, COVELLO P S, MACKENZIE S L, QIU X (2002). High-level production of $\gamma$-linolenic acid in Brassica juncea using a $\Delta 6$ desaturase from Pythium irregulare. Plant Physiol 129: 354-362.

JOBLING S A, WESTCOTT R J, TAYAL A, JEFFCOAT R, SCHWALL G P (2002). Production of a freeze-thaw-stable potato starch by antisense inhibition of three starch synthase genes. Nat Biotechnol 20: 295-299.

KARUNANANDAAB, QIQ, HAO M, BASZIS S R, JENSEN P K, WONG Y-H H, JIANG J, VENKATRAMESH M, GRUYS K J, MOSHIRI F, POST-BEITTENMILLER D WEISS J D, VALENTIN H E (2005). Metabolically engineered oilseed crops with enhanced seed tocopherol. Metab Eng 7: 384-400. 
KEBEISH R, NIESSEN M, THIRUVEEDHI K, BARI R, HIRSCH H-J, ROSENKRANZ R, STÄBLER N, SCHÖNFELD B, KREUZALER F, PETERHÄNSEL C (2007). Chloroplastic photorespiratory bypass increases photosynthesis and biomass production in Arabidopsis thaliana. Nat Biotechnol 25: 593-599.

KIM M-J, KIM J K, KIM H J, PAK J H, LEE J-H, KIM D-H, CHOI H K, JUNG H W, LEE J-D, CHUNG Y-S, HAS-H (2012). Genetic modification of the soybean to enhance the $\beta$-carotene content through seed-specific expression. PloS One 7: e48287.

KINNEY A J, CAHOON E B, DAMUDE H G, LIU Z-B (2011). Production of very long chain polyunsaturated fatty acids in oilseeds plants. US Patent Application US 2011/0269983 A1, 66 United States: E. I. Du Pont de Nemours and Company.

KOHLI A, LEECH M, VAIN P, LAURIE D A, CHRISTOU P (1998). Transgene organization in rice engineered through direct DNA transfer supports a two-phase integration mechanism mediated by the establishment of integration hot spots. Proc Natl Acad Sci USA 95: 7203-7208.

KOHLI A, TWYMAN R M, ABRANCHES R, WEGEL E, STOGER E, CHRISTOU P (2003). Transgene integration, organization and interaction in plants. Plant Mol Biol 52: 247-258.

KOHLIA, GONZÁLEZ-MELENDIP, ABRANCHES R, CAPELLT, STOGERE, CHRISTOU P (2006). The quest to understand the basis and mechanisms that control expression of introduced transgenes in crop plants. Plant Signal Behav1: 185-195.

KRISTENSEN C, MORANT M, OLSEN C E, EKSTRØM C T, GALBRAITH D W, MØLLER B L, BAK S (2005). Metabolic engineering of dhurrin in transgenic Arabidopsis plants with marginal inadvertent effects on the metabolome and transcriptome. Proc Natl Acad Sci USA 102: 1779-1784.

LEE D-S, LEE K-H, JUNG S, JO E-J, HAN K-H, BAE H-J (2012). Synergistic effects of 2A-mediated polyproteins on the production of lignocellulose degradation enzymes in tobacco plants. J Exp Bot 63: 4797-4810.

LI L, PIATEK M J, ATEF A, PIATEK A, WIBOWO A, FANG X, SABIR J S M, ZHU J-K, MAHFOUZ M M (2012). Rapid and highly efficient construction of TALE-based transcriptional regulators and nucleases for genome modification. Plant Mol Biol 78: 407-416.

LÖSSL A, BOHMERT K, HARLOFF H, EIBL C, MÜHLBAUER S, KOOP H-U (2005). Inducible trans-activation of plastid transgenes: expression of the R. eutropha phb operon in transplastomic tobacco. Plant Cell Physiol 46: 1462-1471.

MAJ K-C, HIATT A, HEIN M, VINE N D, WANG F, STABILAP, VAN DOLLEWEERD C, MOSTOV K, LEHNERT (1995). Generation and assembly of secretory antibodies in plants. Science 268: 716-719.

MAQBOOL S B, RIAZUDDIN S, NGUYEN T L, GATEHOUSE A M R, GATEHOUSE J $A, C H R I S T O U ~ P$ (2001). Expression of multiple insecticidal genes confers broad resistance against a range of different rice pests. Mol Breed 7: 85-93.

MAQBOOL S B, CHRISTOU P (1999). Multiple traits of agronomic importance in transgenic indica rice plants: analysis of transgene integration patterns, expression levels and stability. Mol Breed 5: 471-480.

MIRALPEIX B, RISCHER H, HÄKKINEN S T, RITALA A, SEPPÄNEN-LAAKSO T, OKSMAN-CALDENTEY K-M, CAPELL T, CHRISTOU P (2013). Metabolic engineering of plant secondary products: which way forward? Curr Pharm Des 19: 5622-5639.

MOURRAIN P, VAN BLOKLAND R, KOOTER J M, VAUCHERET H (2007). A single transgene locus triggers both transcriptional and post-transcriptional silencing through double-stranded RNA production. Planta 225: 365-379.

MØLDRUPME, GEU-FLORESF, OLSENCE, HALKIERBA(2011). Modulation of sulfur metabolism enables efficient glucosinolate engineering. BMC Biotechnol 11: 12 .

NAQVI S, ZHU C, FARRE G, RAMESSAR K, BASSIE L, BREITENBACH J, PEREZ CONESAD, ROS G, SANDMANN G, CAPELLT, CHRISTOUP (2009). Transgenic multivitamin corn through biofortification of endosperm with three vitamins representing three distinct metabolic pathways. Proc NatlAcad SciUSA 106: 7762-7767.

NAQVIS, FARRÉ G, SANAHUJA G, CAPELL T, ZHU C, CHRISTOU P (2010). When more is better: multigene engineering in plants. Trends Plant Sci 15: 48-56.

NAQVI S, FARRÉ G, ZHU C, SANDMANN G, CAPELL T, CHRISTOU P (2011). Simultaneous expression of Arabidopsis $\rho$-hydroxyphenylpyruvate dioxygenase and MPBQ methyltransferase in transgenic corn kernels triples the tocopherol content. Transgenic Res 20: 177-181.

NICHOLSON L, GONZALEZ-MELENDIP, VAN DOLLEWEERD C, TUCK H, PERRIN Y, MAJ K-C, FISCHER R, CHRISTOU P, STOGER E (2005) A recombinant multimeric immunoglobulin expressed in rice shows assembly-dependent subcellular localization in endosperm cells. Plant Biotechnol J 3: 115-127.
PAINE J A, SHIPTON C A, CHAGGAR S, HOWELLS R M, KENNEDY M J, VERNON G, WRIGHT S Y, HINCHLIFFE E, ADAMS J L, SILVERSTONE A L, DRAKE R (2005). Improving the nutritional value of Golden Rice through increased provitamin A content. Nat Biotechnol 23: 482-487.

PEREMARTIA, TWYMAN R M, GÓMEZ-GALERAS, NAQVIS, FARRÉ G, SABALZA M, MIRALPEIX B, DASHEVSKAYA S, YUAN D, RAMESSAR K, CHRISTOU P, ZHU C, BASSIE L, CAPELLT (2010). Promoter diversity in multigene transformation. Plant Mol Biol 73: 363-378.

PETRASOVITS LA, PURNELL M P, NIELSEN L K, BRUMBLEY S M (2007). Production of polyhydroxybutyrate in sugarcane. Plant Biotechnol J 5: 162-172.

PICHERSKY E, GANG D R (2000). Genetics and biochemistry of secondary metabolites in plants: An evolutionary perspective. Trends Plant Sci 5: 439-445.

PURNICK P E M, WEISS R (2009). The second wave of synthetic biology: from modules to systems. Nat Rev Mol Cell Biol 10: 410-422.

RALLEY L, ENFISSI E M A, MISAWA N, SCHUCH W, BRAMLEY P M, FRASER $P D$ (2004). Metabolic engineering of ketocarotenoid formation in higher plants. Plant J 39: 477-486.

RISCHER H, HÄKKINEN S T, RITALA A, SEPPÄNEN-LAAKSO T, MIRALPEIX B, CAPELL T, CHRISTOU P, OKSMAN-CALDENTEY K-M (2013). Plants cells as pharmaceutical factories. Curr Pharm Des 19: 5640-5660.

ROMANO A, RAEMAKERS K, BERNARDI J, VISSER R, MOOIBROEK H (2003) Transgene organisation in potato after particle bombardment-mediated (co) transformation using plasmids and gene cassettes. Transgenic Res 12: 461-473.

SAYANOVA O V, NAPIER J A (2004). Eicosapentaenoic acid: Biosynthetic routes and the potential for synthesis in transgenic plants. Phytochemistry 65: 147-158.

SIVAMANI E, HUET H, SHEN P, ONG CA, DE KOCHKO A, FAUQUET C, BEACHY R $\mathrm{N}$ (1999). Rice plant (Oryza sativa L.) containing Rice tungro spherical virus (RTSV) coat protein transgenes are resistant to virus infection. Mol Breed 5: 177-185.

STOROZHENKO S, DE BROUWER V, VOLCKAERT M, NAVARRETE O, BLANCQUAERT D, ZHANG G F, LAMBERT W, VAN DER STRAETEN D (2007). Folate fortification of rice by metabolic engineering. Nat Biotechnol 25: 1277-1279.

SUN H, LANG Z, ZHU L, HUANG D (2012). Acquiring transgenic tobacco plants with insect resistance and glyphosate tolerance by fusion gene transformation. Plant Cell Rep 31: 1877-1887.

TOPPING J F, WEI W, LINDSEY K (1991). Functional tagging of regulatory elements in the plant genome. Development 112: 1009-1019.

TU J, ZHANG G, DATTA K, XU C, HE Y, ZHANG Q, KHUSH G S, DATTA S K (2000). Field performance of transgenic elite commercial hybrid rice expressing Bacillus thuringiensis $\delta$-endotoxin. Nat Biotechnol 18: 1101-1104.

TWYMAN R M, KOHLI A, STOGER E, CHRISTOU P (2002). Foreign DNA: integration and expression in transgenic plants. Genetic Engineering: Principles and Methods (Jane K. Setlow Ed.) (N Y) 24: 107-136.

VEGA J M, YU W, HAN F, KATO A, PETERS E M, ZHANG Z J, BIRCHLER J A (2008). Agrobacterium-mediated transformation of maize (Zea mays) with Cre-lox site specific recombination cassettes in BIBAC vectors. Plant Mol Biol 66: 587-598.

VRINTEN P, WU G, TRUKSA M, QIU X (2007). Production of polyunsaturated fatty acids in transgenic plants. Biotechnol Genet Eng Rev 24: 263-280.

WEBER E, ENGLER C, GRUETZNER R, WERNER S, MARILLONNET S (2011). A modular cloning system for standardized assembly of multigene constructs. PLoS One 6: e16765.

WIJEKOON C P, FACCHINI P J (2012). Systematic knockdown of morphine pathway enzymes in opium poppy using virus-induced gene silencing. Plant J69:1052-1063.

WU L, NANDI S, CHEN L, RODRIGUEZ R L, HUANG N (2002). Expression and inheritance of nine transgenes in rice. Transgenic Res 11: 533-541.

YE X, AL-BABILI S, KLÖTI A, ZHANG J, LUCCA P, BEYER P, POTRYKUS I (2000). Engineering the provitamin $A$ ( $\beta$-carotene) biosynthetic pathway into (carotenoidfree) rice endosperm. Science 287: 303-305.

YE G, TU J, HU C, DATTA K, DATTA S K (2001). Transgenic IR72 with fused Bt gene cry $1 A b / c r y 1 A c$ from Bacillus thuringiensis is resistant against four lepidopteran species under field conditions. Plant Biotechnol 18: 125-133.

YU O, SHI J, HESSION A O, MAXWELL C A, MCGONIGLE B, ODELL J T (2003). Metabolic engineering to increase isoflavone biosynthesis in soybean seed. Phytochemistry 63: 753-763.

ZHU C, NAQVIS, BREITENBACH J, SANDMANN G, CHRISTOUP, CAPELLT (2008). Combinatorial genetic transformation generates a library of metabolic phenotypes 
for the carotenoid pathway in maize. Proc Natl Acad Sci USA 105: 18232-18237. ZHU C, SANAHUJAG, YUAND, FARRÉ G, ARJÓ G, BERMAN J, ZORRILLA-LÓPEZ U, BANAKAR R, BAI C, PÉREZ-MASSOT E, BASSIE L, CAPELLT, CHRISTOU P (2013). Biofortification of plants with altered antioxidant content and composition:
Genetic engineering strategies. Plant Biotechnol J 11: 129-141.

ZURBRIGGEN M D, MOOR A, WEBER W (2012). Plant and bacterial systems biology as platform for plant synthetic bio(techno)logy. J Biotechnol 160: 80-90.

\section{Further Related Reading, published previously in the Int. J. Dev. Biol.}

Testicular germ cell tumors and related research from a historical point of view Ivan Damjanov and Nicolai Wewer-Albrechtsen

Int. J. Dev. Biol. (2013) 57: 197-200

Involvement of adipokines, AMPK, PI3K and the PPAR signaling pathways in ovarian follicle development and cancer

Joëlle Dupont, Maxime Reverchon, Lucie Cloix, Pascal Froment and Christelle Ramé Int. J. Dev. Biol. (2012) 56: 959-967

Metabolism throughout follicle and oocyte development in mammals Esther Collado-Fernandez, Helen M. Picton and Rémi Dumollard Int. J. Dev. Biol. (2012) 56: 799-808

\section{Study an egg today to make an embryo tomorrow} Maurizio Zuccotti, Carlo Alberto Redi and Silvia Garagna Int. J. Dev. Biol. (2012) 56: 761-764

Modeling of angioadaptation: insights for vascular development Axel R. Pries, Bettina Reglin and Timothy W. Secomb Int. J. Dev. Biol. (2011) 55: 399-405

Developmental cell biology of human villous trophoblast: current research problems John D. Aplin

Int. J. Dev. Biol. (2010) 54: 323-329

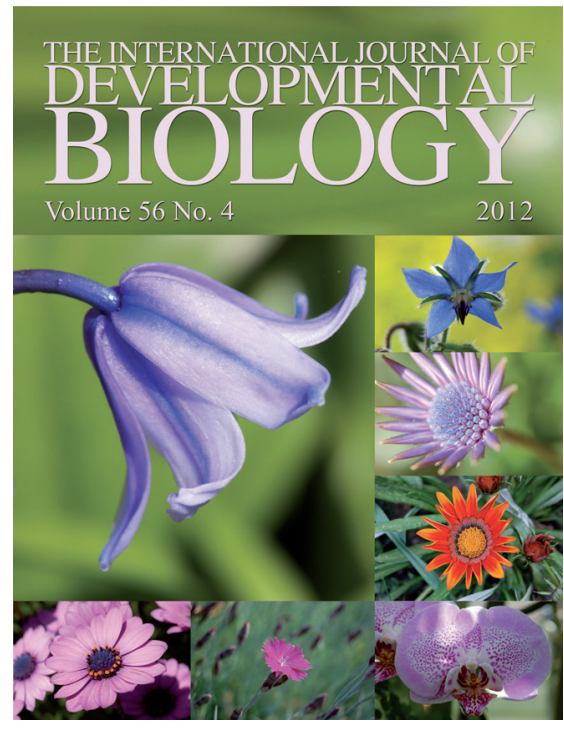

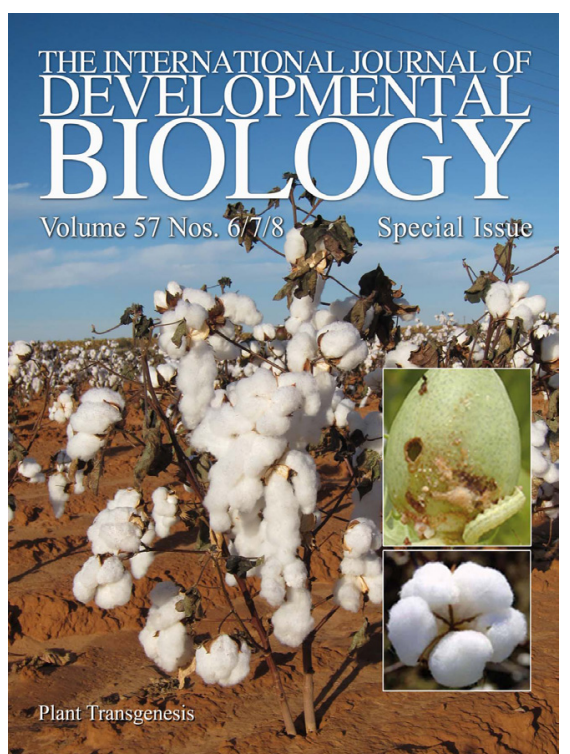

5 yr ISI Impact Factor $(2011)=2.959$

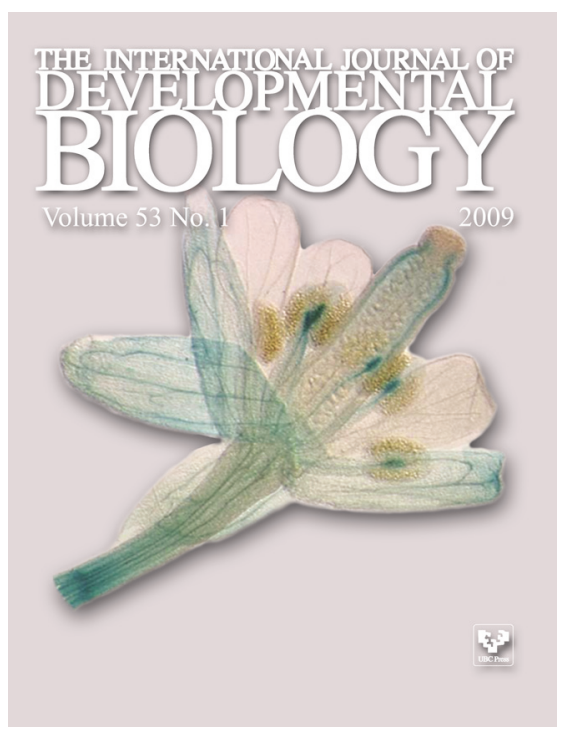

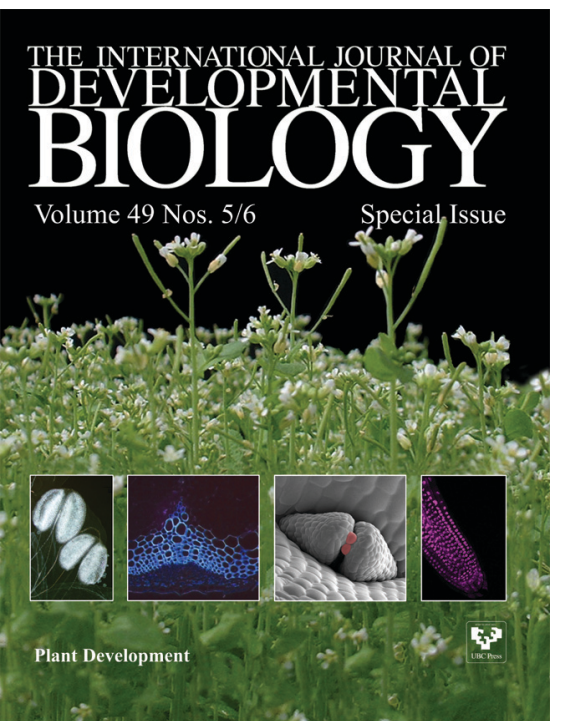

